\title{
Qualidade da educação superior e a tensão entre democratização e internacionalização na universidade brasileira
}

\begin{abstract}
Maria Isabel da Cunha
Resumo: $\mathrm{O}$ texto decorre de uma investigação que toma a democratização e a internacionalização como dois referentes da qualidade da educação brasileira. A primeira aponta para a inclusão de uma população estudantil de primeira geração, em que muitos dos seus integrantes trabalham e estudam, são provenientes de camadas médias da população e, em alguns casos, ingressam através de cotas étnicas ou cotas de escolas públicas, distantes dos padrões anteriores da meritocracia. A outra parece apontar para exigências meritocraticas, envolvendo carreiras de complexidade mais alta, trajetórias estudantis com maiores oportunidades culturais incluindo o domínio de idiomas e disponibilidade de condições para afastar-se do trabalho, entre outras condições. Explorando contribuições de autores que têm se dedicado a explorar o impacto dos dois vetores na educação superior, o texto defende uma democratização na perspectiva cultural e epistemológica que mediará o avanço da internacionalização, quando esta estiver preocupada em favorecer o processo de acumulação de capital de atores hegemônicos. Aposta, também, na importância de uma globalização que se identifica com o trabalho solidário e nos movimentos defensores das identidades culturais que dialogam com os referentes globais. Essa será uma possibilidade de se constituir numa conquista de sistemas educacionais mais justos e numa sociedade mais igualitária.
\end{abstract}

Palavras-chave: Educação superior. Universidade. Democratização e internacionalização.

\section{Quality of higher education and the tension between democratization and internationalization in the Brazilian university}

Abstract: This text is the result of an investigation that takes democratization and internationalization as references of quality in Brazilian education. The first topic points to the inclusion of a first generation population of students, in which many of its members work and study, who belong to the middle class and, in some cases, get into university through racial quotas or coming from public schools, which are away from meritocracy patterns. Internationalization, though, seems to point to meritocratic demands, involving careers of the higher complexity, student paths with bigger cultural opportunities, including foreign languages mastery and availability of conditions to get away from the labour market, among other conditions. By exploring contributions of authors who have been dedicating their efforts to examine the impact of two vectors in higher education, the arguments defend a democratization under cultural and epistemological perspectives that will mediate internationalization advancement, when it gets focused on the benefit of the process of capital accumulation from hegemonic subjects. This text also bets on the importance of a globalization that has identification with solidarity work and movements that defend cultural identities and dialogue with global references. This may be a possibility of constituting an achievement that aims to reach fairer educational systems, in an equitable society.

Key words: Higher education. University. Democratization and internationalization. 


\section{Introdução}

Uma agenda propositiva vem exigindo um aprofundando do conceito de qualidade da educação superior e de como as reflexões políticas e posições epistemológicas incidem sobre os currículos e sobre as práticas de ensinar e aprender que se desenvolvem na universidade. Terão, necessariamente, de cotejar esses processos com os movimentos mais amplos que envolvem as políticas de internacionalização da educação superior e as práticas de avaliação externa. Quantos dilemas nunca foram adequadamente resolvidos? Como as novas configurações estão a exigir revisões dos conceitos consolidados? Que lugares abrigam a discussão desses temas no cenário acadêmico?

Essas são questões mobilizadoras que vêm produzindo estudos e investigações. Como Barnett (2001), acreditamos que "nossas epistemologias não se limitam a existir de maneira isolada. Elas configuram a sociedade e também a refletem. O currículo da educação superior é testemunha desse intercâmbio. O conhecimento legítimo tem sido ampliado e não apenas se ocupa do "o que saber" senão também "do como saber" (p. 75). Essa condição exige atenção e reflexão sobre a qualidade da educação superior e sua relação com uma pedagogia que alicerce o desenvolvimento profissional dos docentes e, finalmente, atinja os estudantes na sua condição aprendente.

A literatura tem apontado que o conceito de qualidade não nos remete a um construto universal, mas são propriedades que se encontram nos seres, ações ou nos objetos. No caso da Universidade, alguns autores, que partem de diferentes posições políticas e filosóficas, acenam para perspectivas distintas do sentido de qualidade da educação superior. Algumas se aproximam mais da visão intelectual-acadêmica e meritocrática; outros da visão economicista e mercadológica e ainda outros de uma vertente que valoriza a dimensão social e emancipatória. Cada uma dessas visões tem desdobramentos em termos do Projeto Pedagógico que constroem, que inclui o currículo dos seus Cursos, as práticas pedagógicas, as culturas acadêmicas, as políticas de pesquisa e extensão, os critérios de avaliação dos estudantes, o investimento em internacionalização, enfim, aquilo que se constitui como expressão de um valor.

É fato, porém, que na universidade há valores em tensão, já que o mesmo acontece na sociedade, revelando movimentos contraditórios que se intercalam em função de interesses diversos e perspectivas divergentes. Trata-se de um campo de lutas, como prescreve Bourdieu (1988). 
Entretanto essas tensões se tornam um interessante objeto de análise quando duas forças, aparentemente em tensão, são desencadeadas pelo mesmo ente político, no caso que estamos analisando, o Ministério da Educação, no contexto de uma agenda global. Referimos à tensão que possa haver entre os processos de democratização e de internacionalização da universidade brasileira. A primeira aponta para a inclusão de uma população estudantil de primeira geração, em que muitos dos seus integrantes trabalham e estudam, são provenientes de camadas médias da população e, em alguns casos, ingressam através de cotas étnicas ou cotas de escolas públicas, distantes dos padrões anteriores da meritocracia. A outra parece apontar para exigências meritocraticas, envolvendo carreiras de complexidade mais alta, trajetórias estudantis com maiores oportunidades culturais incluindo o domínio de idiomas e disponibilidade de condições para afastar-se do trabalho, entre outras condições.

Como, então, compatibilizar projetos acadêmicos aparentemente tensionados? Serão incompatíveis essas duas perspectivas de qualidade universitária? Seria possível uma perspectiva transversal entre elas? A origem e trajetória dos estudantes interferem na compreensão que possuem de qualidade acadêmica? Altera-se no percurso acadêmico? E a perspectiva dos professores? Como compatibilizam distintas compreensões de qualidade? Que repercussões há nas práticas pedagógicas que protagonizam? As políticas acadêmicas acompanham essas expectativas? Preponderam algumas delas?

Esses questionamentos exigiram uma incursão na literatura que vem explorando as questões relativas à qualidade da educação superior no mundo globalizado. Autores como Santos (2002, 2004), Morosini (2006), Cortesão e Stoer (2002), Sharna-Brymer (2013), Beech (2013) Cowen (2013) e outros tem dado significativas contribuições. Procuramos, num diálogo produtivo, compreender suas posições e estabelecer algumas relações com o nosso objeto de estudo.

\section{A globalização: compreensões e impactos}

A globalização passou a ser o conceito de legitimação nos discursos contemporâneos e nas atuais políticas ligadas a economias nacionais e de gestão do estado. Vem impactando de forma especial os processos educativos, especialmente após a segunda grande guerra, com vistas è recuperação da Europa. Fortaleceu-se como agenda principal a partir dos anos noventa, com o fim da guerra fria, encontrando forte aliada na revolução tecnológica que facilitou as comunicações, definiu mercados globais e deu nova configuração aos fenômenos locais. 
Beech (2013) nomeia, principalmente, a UNESCO, a OCDE e o Banco Mundial como principais agências que transitam nesse cenário. Na América Latina, de acordo com o autor, essas agências promoveram visões tecnocráticas e desenvolvimentistas sobre educação nas décadas de 1950 a 1960. Defendiam uma série de tecnologias sociais abstratas - como o planejamento educacional - que, na lógica dominante entre elas, poderiam aperfeiçoar a educação na maioria dos contextos. Com a influência dessa racionalidade técnica, responsável pela introdução de tecnologias sociais como o planejamento educacional e a noção de currículo, houve uma tendência a aumentar a burocracia e a divisão do trabalho nos sistemas educacionais da América Latina.

A transferência de conhecimento educacional é considerada, atualmente, um dos principais papéis da UNESCO, do Banco Mundial e da OCDE.

Cada uma dessas agências tem propostas específicas para a educação. O Banco Mundial defende que as reformas educacionais devem ser orientadas para acompanhar as estruturas econômicas, ou seja, "suprir as crescentes demandas das economias por trabalhadores adaptáveis" (WORLD BANK, 1995).

A UNESCO traz uma perspectiva mais humanística que situa o ser humano no epicentro do desenvolvimento, ou seja, "voltar-se para o pleno desenvolvimento da personalidade humana e o fortalecimento do respeito aos direitos e liberdades fundamentais [...] devendo promover o entendimento, a tolerância e a amizade entre as nações e todos os grupos raciais e religiosos" (MAYOR; SAMA, 1997, p. 89).

A Organização de Cooperação e Desenvolvimento Econômico, OCDE, situa-se entre a perspectiva humanista da UNESCO e a ênfase do Banco Mundial nos aspectos econômicos. Tem posições conflitantes entre algumas políticas de ambas as agências, de acordo com Beech (2013).

As três agências, entretanto, têm posições similares na sua forma de ver o futuro como a era da informação. A partir dessa premissa convergem na proposta de um "modelo ideal para a educação", produzindo "um discurso educacional global”, apostando num modelo universal de educação como estratégia global capaz de resolver a maioria dos problemas educacionais nos mais diversos contextos locais. Um exemplo dessa perspectiva foram as políticas dos anos 90, assumindo discurso das competências como referente dos currículos escolarizados.

A organização da comunidade europeia acelerou o processo e, por conseguinte, a produção analítica sobre a globalização nos diversos setores da organização social. A educação constitui-se num eixo importante para o alcance dos objetivos, especialmente tendo 
em vista a criação de mão de obra capacitada para adaptar-se às necessidades da economia. Estudos e pesquisas - nem sempre coincidentes - focaram a questão da globalização e o papel da União Europeia no contexto de competitividade econômica do hemisfério norte.

Dale (1999) explora os mecanismos que favoreceram a adesão aos referentes das agências internacionais e menciona os empréstimos financeiros para projetos educacionais como um principal dispositivo de adesão dos estados nacionais. Menciona etapas desses mecanismos que incluem a harmonização, a disseminação, a estandardização, a implantação da interdependência até chegar à imposição, como é caso da validação dos empréstimos feitos pelo Banco Mundial. O autor ajuda-nos a compreender a educação como campo de transnacionalização, aprofundando as ligações entre as mudanças na economia global e mudanças na política e prática educativa.

Lembram Cortesão e Stoer (2002), recorrendo aos conceitos de Santos, que a educação é simultaneamente um localismo globalizado e um globalismo localizado. Os localismos globalizados consistem nos processos pelo qual determinado fenômeno local é globalizado. Um exemplo do localismo globalizado refere-se a aceitação da defesa da escola oficial, gratuita e laica, uma escola para todos, presente no estado republicano. Trata-se de um globalismo europeu que se tornou um referente internacional.

Já o globalismo localizado refere-se ao impacto específico de práticas interpretativas transnacionais às condições locais e se manifesta através do esforço dos estados nacionais em conciliar a formação adaptada à economia global. Busca manter uma identidade cultural local. Quanto mais periférica é uma nação, mais esse processo se desequilibra provocando movimentos neo-coloniais.

Santos (1997), entretanto, tem explorado outras possibilidades, mencionando a globalização de-baixo-para-cima ou contra hegemônica, denominada pelo autor de cosmopolitismo ou patrimônio comum da humanidade.

Para Santos, a globalização é

\begin{abstract}
o processo pelo qual determinada condição ou entidade local estende a sua influência a todo o globo e, ao fazê-lo desenvolve a capacidade de designar como local outra condição social ou entidade rival. [...] Não existe globalidade genuína; aquilo que chamamos globalização é sempre a globalização bem sucedida de determinado localismo. [...] globalização pressupõe localização (1997, p. 14)
\end{abstract}

Que reflexos teria essa possibilidade no campo educacional?

Cortesão e Stoer trazem o conceito bourdiniano de campo para pensar as determinações que as relações objetivas da globalização impõe aos agentes educacionais. 
Lembram que, para Bourdieu (1988, p. 72) “o campo pode ser definido como uma rede, ou uma configuração de relações objetivas entre posições". O importante é compreender as relações de poder, pois o conceito de campo estimula a pensar que "num campo há lutas e, portanto história" (p. 78), Os autores registram que ocupam o espaço do campo tanto os dominadores, como os dominados.

Essas considerações são importantes para se considerar que as forças que envolvem o fenômeno da globalização são diversas e, às vezes, contraditórias. Como afirmam Cortesão e Stoer (2002), há uma encruzilhada de forças centrípetas e centrífugas de transnacionalização da educação (p. 383). Assim como os países são objetos das políticas globais, vão, também, definindo resignificações desses discursos a nível local.

Utilizando as propostas de Santos (1995), os autores Cortesão e Stoer (2002, p. 393) propõem um quadro conceitual para análise do campo educativo que inclui sete formas de transnacionalização, termo utilizado pelo autor como similar à globalização. São eles: "transnacionalização de políticas educativas"; "processos de "mercadorização da educação"; "políticas educativas de integração regional"; "processos de educação de migrantes ou grupos minoritários"; "processos educativos de que dispõem de grupos transnacionais"; “desenvolvimento de um projeto de educação cosmopolita" e, o ultimo, "questões universais". Dessas, tomaremos duas que parecem melhor se adequar ao caso brasileiro e os objetivos do estudo que serve de base a estas reflexões. Refiro-me aos processos de mercadorização da educação e desenvolvimento de um projeto de educação cosmopolita. Os dois estão nas pontas de processos conflitantes, mas, certamente, presentes na realidade da educação brasileira.

No contexto dos processos de mercadorização da educação localizam-se as ofertas de peritos e organizações a respeito de projetos de currículos internacionais tendo com pressuposto a modernização e a aculturação. Incluem propostas de grupos internacionais materializadas em ofertas de cursos e instituições de ensino. Valem-se das práticas homogêneas de avaliações para promover propostas universais de qualidade, inseridas nos "pacotes" educacionais e materiais instrucionais. A nível de sistemas, impactam as reformas educativas e a regulação. Criam um mercado educacional, onde "a escola de massas é subvertida pela massificação do ensino" (CORTESÃO; STOER, 2002, p. 395).

A educação cosmopolita, por outro lado, valoriza a cultura local, ainda que, em geral, expõe a cultura dominante, erudita, valorizando o conhecimento validado pela ciência e as produções culturais que envolvem desde o cinema e as artes plásticas até as revistas científicas que pretendem explicitar o pensamento intelectual do país na interface com os 
demais. Reivindicam a cultura local nas formulações curriculares e no diálogo com as perspectivas internacionais.

Numa análise ampla, é possível identificar essas duas tendências no processo de internacionalização da educação brasileira. Ao mesmo tempo em que há uma invasão de grupos internacionais fazendo ofertas educativas, especialmente para a educação superior, há um investimento na produção de conhecimento local, através de pesquisas e estudos que procuram responder aos desafios da realidade brasileira na intenção do cosmopolitismo. Basta ver a abundante e crescente indústria editorial que assume especial destaque na produção intelectual de língua portuguesa. A questão cultural aparece com vigor, dependendo das políticas de incentivo, mas presente no panorama internacional. Há estímulo para o diálogo acadêmico - bolsas de estudo com patrocínio do estado nacional - com a intenção de colocar o país na condição de interlocutor reconhecido na produção e disseminação do conhecimento a nível mundial.

Esses movimentos podem revelar forças contraditórias, mas, também possibilidades convergentes. É complexo, em termos de políticas públicas e práticas educativas, definir limites que expressem a intencionalidade da emancipação cultural com a dominação presente nos processos neo-coloniais.

\section{Democratização da educação: perspectivas em ação}

As forças da internacionalização se instalam nos contextos nacionais, com suas peculiaridades e desafios. No caso do Brasil, os processos de democratização da educação superior tem constituído a agenda nacional e provocado políticas que procuram avançar nesse sentido.

Historicamente marcada pela expansão através da rede privada, a educação superior do país tem estado aquém das necessidades nacionais, quer em quantidade, quer em qualidade.

Até então, as universidades públicas têm sido um referente dos processos de formação, tanto pelo ensino de graduação e pós-graduação que desenvolvem, quanto pela extensão e impacto da pesquisa. Seus professores atuam, em grande maioria, em regime de dedicação exclusiva e são recrutados a partir dos títulos de mestres e doutores. Algumas universidades comunitárias e confessionais se aproximam do mesmo patamar.

Outras tantas instituições são privadas com fins lucrativos e se caracterizam como grandes conglomerados de campus, espalhados pelo país, com propostas de formação de baixo custo, nem sempre de qualidade reconhecida, mesmo que não se possa fazer 
generalizações. Algumas, inclusive, decorrem de capital internacional. Há, ainda, um grande numero de instituições privadas isoladas que se dedicam apenas à atividades de ensino, afastando-se do referente acadêmico desejado.

Esse cenário justificou a expansão das instituições públicas de ensino superior no Brasil, a partir de 2002. Foram criadas novas universidades públicas, em geral interiorizadas, e/ou expandidas as historicamente existentes. Também houve a criação dos Institutos Federais de Educação Tecnológica e Profissional, transformando a rede anterior em um significativo sistema público, que também faz a oferta de ensino superior e tem o compromisso de realizar ensino, pesquisa e extensão.

Desde o inicio da implantação dessa política governamental, a oferta das vagas publicas aumentou significativamente, alcançando rincões do país antes nunca imaginados. Não houve, entretanto, significativa mudança na relação publico-privado, porque também as instituições privadas estiveram em expansão, inclusive pela política governamental que isenta universidades privadas de encargos e impostos, em troca de vagas gratuitas para estudantes de baixa renda Mas é preciso reconhecer que a oferta de vagas em instituições públicas vem propiciando a presença de uma massa estudantil até então alijada dessa oportunidade.

A democratização, além da oferta de vagas, inclui as condições objetivas para a permanência estudantil. Nesse contexto uma política própria foi implantada e/ou expandida, envolvendo acessibilidade e apoio (alimentação, moradia, transporte, saúde) para muitos estudantes de baixa renda. Também vem sendo implementadas políticas institucionais de acompanhamento de estudos para garantir uma taxa de sucesso razoável, tendo em vista o investimento despendido.

Essas políticas tem o reconhecimento publico de que são necessárias ao processo de democratização do acesso à universidade.

Entretanto, temos considerado que elas não esgotam o sentido da democratização. Num pais como o Brasil, com profundas sequelas históricas e exigências de diminuir o abismo entre as classes sociais, é preciso que a democratização signifique muito mais. É preciso democratizar o conhecimento, suas formas de produção e a relação entre a universidade e a sociedade.

A educação superior pública tem compromisso com a maioria da população que a sustenta e o conhecimento que produz deve ter o compromisso social como referente, além da realização pessoal do educando. Isto significa que a democratização se faz pela compreensão de conhecimento, atravessada por uma ética coletiva do bem comum. 
Nesse sentido outra relação de poder precisa ser reivindicada pela universidade democratizada. Aquela que se coloque contra a monocultura do saber, onde o saber científico saiba dialogar com outros saberes e avance em direção da anulação daquilo que Santos denomina de sociologia das ausências (2004), onde não há ignorância em geral nem saber em geral. Toda a ignorância refere-se a certo saber e todo saber é a superação de uma ignorância em particular. Para o autor, o confronto e o diálogo entre saberes se constitui num confronto e diálogo entre diferentes processos através dos quais práticas diferentemente ignorantes se transformam em práticas diferentemente sábias. Neste domínio, a sociologia das ausências visa substituir a monocultura do saber científico por uma ecologia dos saberes (p. 790).

A questão da democratização do conhecimento (incluindo aí as agencias como a escola e a universidade) está na aposta da reconfiguração de saberes. Isto significa a função da extensão ao inverso da tradição, segundo ele. Ao invés da universidade levar o seu conhecimento para a sociedade, ela deve se abrir para que a sociedade adentre a universidade, trazendo, também, os seus saberes. Significa anular/diminuir o reconhecimento do saber numa escala de poder e legitimidade. Todos os saberes são legítimos desde que eles contribuam para o bem estar comum.

O mesmo paradigma seria possível para a análise da internacionalização? Significaria distanciar-se da ideia colonizadora que classifica saberes e instituições, numa relação de dependência que tem apenas o chamado "saber científico" como parâmetro de legitimado. Para Santos, "o conhecimento válido é aquele em que acreditamos" (2015). Colonização/dominação significa deixar de crer no conhecimento próprio.

O autor defende que a política é epistemológica e por isso precisamos de outra epistemologia, que reconheça a sociologia das ausências. Vem apontando que ajudariam a compreender a epistemologia que se estabelece como reconfiguração de sabres. Uma delas é a mudança do conhecer sobre para o conhecer com. Há, ainda a necessidade de uma reflexão sobre quem é o outro. Mas, também, de recuperar o valor do trabalho coletivo em prol de todos (recuperar a ideia de mutirão), ao invés de entender o conhecimento como produto e direito individual.

A reconfiguração dos saberes, que envolve uma ecologia, requer uma ruptura paradigmática porque pressupõem a anulação ou diminuição das clássicas dicotomias propostas pela modernidade. Inclui uma junção do ser e do saber, e a anulação das dicotomias entre saber popular e saber científico; ciência e cultura; teoria e prática; corpo e alma etc (CUNHA, 1995). Pressupõe uma visão integradora dos processos humanos de ensinar e aprender e envolve a categoria da totalidade para compreender os contextos de produção de 
sentido. Implica numa abordagem pós-colonial, levando em conta como tratar, abordar, entender a opinião e a posição do "outro" (SHARNA-BRYMER, 2012).

Que impactos acadêmicos uma democratização que se pauta por esta perspectiva pressupõem? Como os currículos dos cursos de uma universidade que se democratiza serão atingidos? Que papel terão os contextos locais e as comunidades nessa definição? Que rearranjos serão necessários nas relações professor-alunos? Como essa epistemologia provocará uma nova prática pedagógica? Que sentido é dado à experiência nesse processo? O que será importante na avaliação?

Certamente essa compreensão de democratização será bem mais exigente do que a que aponta com exclusividade para as políticas de permanência e assistência estudantil. Trata-se de uma mudança paradigmática e política, que exige engajamento, coragem, humildade e criatividade.

\section{3 É possível alguns referentes comuns para analisar os movimentos de globalização/ internacionalização e de democratização?}

Certamente há implicações específicas para a criação de referentes que consigam iluminar a compreensão desses dois movimentos em tensão: globalização/internacionalização e democratização da educação superior no Brasil. Entretanto, ousamos especular que há elementos comuns a essa análise, que podem ser úteis para tomar a questão da qualidade da educação superior na sua complexidade. Trataremos de apontar algumas possibilidades.

a) Quem é o outro? Um dos referentes interessantes pode estar na resposta a essa pergunta, tanto nos processos de democratização como na internacionalização. É provável que haja uma significativa escala de apreciação e/ou depreciação da figura do outro, nesses dois contextos.

Nos processos de internacionalização o outro pode estar num patamar superior de conhecimento em relação ao aprendente. Há uma escala de valor e um imaginário social que em outros países se faz melhor educação do que no Brasil e que há maior desenvolvimento em ciência e tecnologia. O aprendiz sai do país para aprender com quem "sabe mais", usufruir de melhores estruturas acadêmicas, professores mais preparados, laboratórios mais equipados, bibliotecas especializadas e oportunidades de crescimento pelo convívio acadêmico de ponta, aperfeiçoamento da língua dominante. Lá, em geral, o estudante tupiniquim é visto como o outro, sente-se como o outro, vive preconceitos como o outro, fala como o outro. Em geral, 
precisa um tempo e muito esforço para mostrar seu valor e condição de interlocutor. Não é atoa que, em geral, seus parceiros cotidianos são "outros outros", de nacionalidade, de condição de estrangeiro, de afinidade cultural, de resiliência frente ao novo.

Nos processos de democratização o outro é o exógeno à universidade, aquele que, em geral, está em posição inferior em relação ao conhecimento científico e é possuidor de um conhecimento do senso comum, prático, que pouco valor tem na academia. Há, também, uma estrutura de poder nessas relações com expressiva desvalorização do interlocutor, quer por classe social, quer por diferença cultural. Em algumas situações o outro tem marcas étnicas, religiosas e de gênero, suscetíveis de preconceito. Nesse caso pode haver um reconhecimento de relações mais horizontais, mas uma supremacia do discurso acadêmico que se reveste de verdade. Em geral há pouca convivência e troca de saberes com o outro, que só é reconhecido como alguém em condições subalternas.

b) Que etapas marcam as relações epistemológicas com o outro?

Para Cowen (2012), tomando o referente dos estudos de educação comparada, há três etapas/momentos caracterizadores dessas relações, em ordem crescente de autonomia:

- a transferência que se refere à condição de aplicar políticas e práticas de um contexto em outro, em geral em condições de dependência cultural, econômica e social.

- a tradução que revela a condição de realizar uma releitura das políticas e práticas, sem alterar a sua essência, para realidades distintas.

- a transformação, onde o conhecimento do outro é ponto de referência para o desenvolvimento das culturas próprias.

Os dois primeiros, transferência e transformação referem-se à inclusão de ideias, princípios, políticas e práticas educacionais sem, entretanto, resignificá-los em outro contexto social. Não se configurariam em pleno como uma reconfiguração de sabres, ainda que a tradução faça um movimento nessa direção. Para que ela aconteça, a compreensão dos dois polos de produção do conhecimento é importante.

A transferência se aproxima das políticas neo-colonizadoras que impõem padrões e regimes de verdade de uma cultura para outra. Em geral assumem um discurso de supremacia, dividindo pessoas, políticas e culturas e dicotomizando o certo do errado, o moderno do arcaico, o inovador do tradicional, o progressista do conservador. Assume uma condição messiânica de ingenuidade política. Não assume a condição dialógica e se apresenta como redentor e salvador dos despossuídos ou menos desenvolvidos. A transferência, entretanto, em 
geral trai aos seus seguidores, pois as culturas locais resignificam os discursos, estabelecem juízos de valor e materializam resistências. Estas, nem sempre são explícitas, mas solapam o sucesso das políticas e saberes impostos.

A tradução aposta um pouco mais na necessidade da interlocução entre pessoas, culturas e comunidades. Toma os princípios geradores de uma política, cultura ou saberes e procura adaptar aos contextos locais. Lança mão de estratégias de convencimento, mas é capaz de negociações. Reconhece o saber do outro, ainda que o mantenha predominantemente em condição subalterna. Procura uma afinidade de linguagem e exerce a empatia para captar o outro em direção ao conhecimento que considera válido. Encontra mais transparência nas resistências e se dispõe a negociações e concessões. Alcança resultados parciais nas proposições, mas crê que é nesse ritmo que pode avançar no seu intento.

A transformação se constitui num processo mais raro, pois supõe a anulação das relações de poder e essa é uma condição complexa, desde o discurso acadêmico. Nela estaria a aposta na reconfiguração de saberes em posições horizontais, onde todos são reconhecidos como portadores de conhecimentos que exigem inter-relação. Mais do que levar o conhecimento científico para fora da universidade, reconhece que é importante trazer o conhecimento prático e vivencial para dentro da universidade, invertendo práticas de grande tradição.

$\mathrm{Na}$ transformação, todos os atores se modificam, se iluminam um com o saber do outro. Há o reconhecimento da diferença, mas num patamar de igualdade. O produto da transformação é um amálgama de saberes que respondam com mais adequação aos contextos sociais.

c) Que referente epistemológico sustenta a democratização do conhecimento?

Para Santos essa perspectiva envolve, especialmente:

- a sociologia das ausências que visa substituir a monocultura do saber dominante pela ecologia dos saberes. O importante é identificar os contextos em que cada sociedade ou sujeito opera, e o modo como concebem a realidade. O exercício da sociologia das ausências tem lugar através da confrontação com o saber científico tradicional e exige imaginação sociológica. Para tal é importante dois tipos de imaginação: a epistemológica e a democrática. A primeira permite diversificar saberes, as perspectivas e escalas de identificação, análise e avaliação das práticas. A segunda leva ao reconhecimento de diferentes práticas e grupos sociais (2004, p. 793), mas se afasta da arrogância colonial de determinar quem é igual e quem é diferente, numa relação de superioridade. 
- a reconfiguração dos saberes, além de anular escalas de importância e legitimidade entre saberes e suas formas e lugares de produção, permite e estimula projetar o futuro, aquilo que ainda não é, alimentando expectativas e autorias, o que Santos denomina de sociologia das emergências. Enquanto a sociologia das ausências expande o domínio das experiências sociais já disponíveis, a sociologia das emergências expande o domínio das expectativas. Quanto mais experiências estiverem hoje disponíveis no mundo, mais experiências serão possíveis no futuro (2004, p. 799).

Nenhuma destas alternativas refere-se exclusivamente ao conhecimento científico e aos aspectos unicamente cognitivos. As três envolvem posições políticas e sociais, envolvem sentimentos, vida privada, societária e cultural. As escolhas dependem mais do referente de valores dos grupos e instituições do que de planos previamente testados. Sempre, entretanto haverá uma intencionalidade e uma expectativa. E a força indutora das políticas globais.

Sharma-Bryner (2012) também contribui para o exercício de compreensão das tensões e dilemas do estudante numa sociedade pós-colonial, onde os processos de globalização são recorrentes e definidores de padrões de qualidade. Ainda que a perspectiva pós-colonial esteja distante da realidade brasileira em relação à Portugal, pode ser útil registrar a presença de outros formatos de colonização que estiveram presentes na sociedade contemporânea. Os efeitos da influência europeia sobre as práticas sociais e escolarizadas no Brasil foram se sucedendo ao longo do século XX. Marcadamente a França foi o referente até os anos cinquenta e, no pós-guerra, a relação do Brasil com o Bloco Aliado, redirecionou a condição de dependência para os EEU, nos aspectos políticos, econômicos e culturais. Portanto, o país sempre foi tributário de decisões externas, numa internacionalização pouco discutida. Nesse sentido a aculturação dos currículos e das teorias pedagógicas se constituiu em um forte dispositivo de legitimação do modelo exógeno.

Hoje a mobilidade dos estudantes através de programas institucionalizados demanda uma sensibilidade particular com o que Sharma-Bryner denomina de híbridos educados e migrantes deslocados. A autora explora as condições de se constituir num outro, mesmo com características similares aos companheiros nativos. Diz ela:

O outro está em toda a parte e ao nosso redor. Ela pode ser culta e formada na Universidade de Sri Lanka, que luta para exprimir seu pensamento em inglês em uma universidade australiana; ele um consultor indiano especializado em TI e vive na Califórnia e se esforça para encontrar lugar na comunidade branca; um terceiro pode ser um africano que se debate com um dilema quanto a seguir ou não os hábitos culturais de seus pais. [...] Os 
diversos efeitos da globalização aumenta as tensões. Como, então, ouvir a voz do outro?" (SHARMA-BRYNER, 2012, p. 16)

A autora reforça sua intenção de tencionar sobre o que se perde e o que se ganha no processo de tornar-se um hibrido em tempos de globalização; de que forma os híbridos tentam se relocalizar em um terceiro espaço que não é o seu de origem e nem acena por outro com estabilidade. As tensões e contradições na busca deste terceiro espaço de deslocamento e busca das conexões entre eles torna-se um projeto bem desafiador.

Seria possível esboçar uma relação dos híbridos educados e migrantes deslocados.no cenário da democratização da universidade brasileira? Mesmo não se tratando de processos de internacionalização, muitos estudantes se reconhecem com estrangeiros numa cultura que, até então, lhe é desconhecida. Precisam ser aceitos na sua condição cultural, aprender a se expressar segundo as normas acadêmicas; ser aceito como parte de uma comunidade de especialistas e incorporar valores e normas, muitas vezes distantes de suas realidades. Mais do que isto, frequentemente necessitam submeter-se a um conhecimento imposto e distante de seus contextos e interesses.

Com estas reflexões, assumimos a perspectiva de que democratização e globalização se constituem, hoje, em duas faces da moeda corrente que valida a qualidade do ensino superior no Brasil. Será importante dar conta das duas com intencionalidade e espírito crítico para poder ter um avanço nas duas frentes, sempre que elas contribuírem para o bem estar comum.

O empenho na democratização na perspectiva cultural e epistemológica é que poderá conter o avanço da internacionalização, quando preocupada em favorecer o processo de acumulação de capital de atores hegemônicos.

Investir numa globalização que aposta no trabalho solidário e nos movimentos defensores das identidades culturais que dialogam com os referentes globais, é que pode se constituir numa conquista de sistemas educacionais mais justos e numa sociedade mais igualitária.

Arnove lembra que entender o mundo é uma chave para mudá-lo para melhor (2012, p. 149), favorecendo políticas e práticas mais esclarecidas com vistas ao entendimento e a paz para todos. Estará aí a nossa possibilidade? 


\section{Referências}

ARNOVE, Robert. Análise dos sistemas-mundo e educação comparada na era da globalização. In: COWEN, Robert; KAZAMAS, Andreas; UNTERALTER, Elaine (Orgs.). Educação comparada: panorama internacional e perspectivas. Brasília: UNESCO/CAPES, 2012. v. 2. p. 131-152.

BARNETT, Ronald. Los limites de la competencia: el conocimiento, la educación superior y la sociedad. Barcelona: Gedisa Editorial, 2001.

BEECH, Jason. Quem está passeando pelo jardim global? Agências Educacionais e Transferência Educacional. In: COWEN, Robert; KAZAMAS, Andreas; UNTERALTER, Elaine (Orgs.). Educação comparada: panorama internacional e perspectivas. Brasília: UNESCO/CAPES, 2012. v. 2. p. 413-433.

BOURDIEU, Pierre. O campo científico. São Paulo: Ática, 1988. (Coleção Os Pensadores).

CORTESÃO, Luisa; STOER, Stephen. Cartografando a transnacionalização do campo educativo: o caso português. In: SANTOS, Boaventura de Sousa. A globalização e as ciências sociais. São Paulo: Cortes, 2002. p. 377-414.

COWEN, Robert. Introdução: o nacional, o internacional e o global. In: COWEN, Robert; KAZAMAS, Andreas; UNTERALTER, Elaine (Orgs.). Educação comparada: panorama internacional e perspectivas. Brasília: UNESCO/CAPES, 2013. 2012. v. 1. p. 407-412

CUNHA, Maria Isabel da. O professor universitário na transição de paradigmas. Araraquara/SP: Junqueira\& Marin Editora, 1995.

DALE, Roger. Specifying globalization effects on national policy: a focus on the mecanisms. Journal of Education Policy, London, v. 1, n. 14, p. 1-17, 1999.

MAYOR, T.; SAMA, T. UNESCO: an ideal in action; the continuing relevance of a visionary text. Paris: UNESCO, 1997. p. 89-101.

MOROSINI, Marilia Costa. Estado do conhecimento sobre internacionalização da educação superior -conceitos e práticas. Educar. Curitiba, n.28, p.107-127, 2006.

SHARMA-BRYNER, Vinathe. Reflexões sobre pós-colonialismo e educação: tensões e dilemas de uma vivenciadora. In: COWEN, Robert; KAZAMAS, Andreas; UNTERALTER, Elaine (orgs.). Educação comparada: panorama internacional e perspectivas. Brasília: UNESCO/CAPES, 2012. v. 2. p. 15-30.

SANTOS, Boaventura de Sousa. Towrd a new commom sense. Law, Science and politics en the paradigmatic transition. Nova Yorque:Routledge, 1995.

SANTOS, Boaventura de Sousa. Por uma educação multicultural de direitos humanos. Revista Crítica de Ciências Sociais, Coimbra, n. 48, p. 11-32, 1997.

SANTOS, Boaventura de Sousa (Org.). A globalização e as ciências sociais. São Paulo: Cortez, 2002.

SANTOS, Boaventura de Sousa. Para uma sociologia das ausências e uma sociologia das emergências. In: SANTOS, Boaventura de Sousa (Org.). Conhecimento prudente para uma vida decente. São Paulo: Cortez, 2004.

SANTOS, Boaventura de Sousa. Conferência proferida na XXXVII Reunião da Latin American Studies Association LASA. São José, Porto Rico, maio de 2015. 
WORLD BANK. Priotitis and strategies for education: a World Bank sector review. Washington, Dc, World Bank, 1995.

Maria Isabel da Cunha - Universidade do Vale do Rio dos Sinos São Leopoldo | RS | Brasil. Contato: cunhami@uol.com.br

Artigo recebido em 23 de fevereiro de 2016 e aprovado em 10 de abril de 2017. 